\title{
Effects of aerobic exercise performed in fasted $v$. fed state on fat and carbohydrate metabolism in adults: a systematic review and meta-analysis
}

\author{
Alexandra Ferreira Vieira ${ }^{2 *}$, Rochelle Rocha Costa $^{1,2}$, Rodrigo Cauduro Oliveira Macedo ${ }^{1,3}$, \\ Leandro Coconcelli ${ }^{1,2}$ and Luiz Fernando Martins Kruel ${ }^{1,2}$ \\ ${ }^{1}$ Physical Education, Physiotherapy and Dance School, Federal University of Rio Grande do Sul, 750, Felizardo Street, \\ 90690-200 Porto Alegre, Brazil \\ ${ }^{2}$ Research Group on Water and Land Activities, Federal University of Rio Grande do Sul, 750, Felizardo Street, \\ 90690-200 Porto Alegre, Brazil \\ ${ }^{3}$ Research Group on Exercise Physiology and Biochemistry, Federal University of Rio Grande do Sul, 750, Felizardo Street, \\ 90690-200 Porto Alegre, Brazil
}

(Submitted 7 March 2016 - Final revision received 29 July 2016 - Accepted 3 August 2016 - First published online 9 September 2016)

\section{Abstract}

This study aimed to verify the effect of aerobic exercise performed in the fasted $v$. fed states on fat and carbohydrate metabolism in adults. Searches were conducted in March 2015, and updated in July 2016, using PubMed ${ }^{\circledR}$, Scopus and Cochrane databases (terms: 'fasting', 'exercise', 'aerobic exercise', 'substrate', 'energy metabolism', 'fat', 'glucose', 'insulin' and 'adult') and references from selected studies. Trials that compared the metabolic effects of aerobic exercise (duration $\leq 120 \mathrm{~min}$ ) performed in the fasted $v$. fed states in adults were accepted. The outcomes evaluated were fat oxidation during exercise and the plasma concentrations of insulin, glucose and NEFA before and immediately after exercise; two independent reviewers extracted the data (A. F. V. and L. C.). The results were presented as weighted mean differences between treatments, with $95 \%$ CI. Of 10405 articles identified, twenty-seven studies - with a total of 273 participants - were included. There was a significant increase in fat oxidation during exercise performed in the fasted, compared with fed, state $\left(-3.08 \mathrm{~g} ; 95 \% \mathrm{CI}-5 \cdot 38,-0 \cdot 79 ; I^{2}\right.$ $39 \cdot 1 \%)$. The weighted mean difference of NEFA concentrations was not significantly different between states $(0.00 \mathrm{mmol} / \mathrm{l} ; 95 \% \mathrm{CI}-0.07$, $\left.0.08 ; I^{2} 72 \cdot 7 \%\right)$. However, the weighted mean differences of glucose $\left(0.78 \mathrm{mmol} / 1 ; 95 \% \mathrm{CI} 0.43,1 \cdot 14 ; I^{2} 90 \cdot 8 \%\right)$ and insulin concentrations (104.5 pmol/1; $95 \%$ CI 70.8, 138.2; $I^{2}$ 94.5\%) were significantly higher for exercise performed in the fed state. We conclude that aerobic exercise performed in the fasted state induces higher fat oxidation than exercise performed in the fed state.

\section{Key words: Fasting: Exercise: Energy metabolism: Reviews}

Fasting is characterised by the absence of food and/or energy beverage intake for a period of time, which may last from several hours to a few weeks ${ }^{(1,2)}$. However, most people fast for 8-12 h daily - the 'overnight fasting' period ${ }^{(2)}$. During this period, NEFA, ketone bodies and glucose derived from liver glycogen and gluconeogenesis are the predominant energy sources ${ }^{(3)}$.

During exercise, NEFA also make a considerable contribution to energy metabolism owing to the increased availability of these substrates in the plasma. This is caused by increased adrenaline levels and decreased insulin concentrations in the blood $^{(4)}$. Fasting promotes low levels of insulin and hepatic glycogen ${ }^{(2)}$. Thus, when aerobic exercise is performed under these conditions, an increase in the utilisation of fat as an energy substrate is observed, when compared with exercise performed in the fed state ${ }^{(5,6)}$. The decrease in fat oxidation during exercise in the fed state can be mainly attributed to higher insulin concentrations caused by a meal, which may inhibit the breakdown of intramuscular TAG (IMTG) and reduce the availability of NEFA for oxidation ${ }^{(7,8)}$.

Several studies have indicated that regular exercise promotes beneficial effects in terms of health and body composition ${ }^{(9-11)}$, including an improvement in insulin sensitivity and maintenance and reduction of body weight and body fat. It has been suggested that exercise enhances fat oxidation and that this adaptation may be associated with improved insulin sensitivity ${ }^{(12)}$. Furthermore, higher fat oxidation capacity during exercise seems to be related to a decrease in the number of metabolic risk factors ${ }^{(13)}$. Venables \& Jeukendrup ${ }^{(14)}$ demonstrated that participating in a training programme for 4 weeks, with continuous aerobic exercise programmed for the maximum contribution of fat as the energy substrate during each session, can further increase fat oxidation. This higher oxidation was associated with improvements in insulin sensitivity in obese men. In healthy, young men, the maximal fat oxidation

\footnotetext{
Abbreviation: IMTG; intramuscular TAG.
}

* Corresponding author: A. F. Vieira, fax +55 513308 5820, email alexandrafvieira@hotmail.com 
during exercise was positively associated with insulin sensitivity and $24-\mathrm{h}$ fat oxidation ${ }^{(15)}$. Studies have demonstrated that exercise performed in the fasted state can increase the rate of fat oxidation at rest from $9^{(16)}$ to $24 \mathrm{~h}^{(17-19)}$ after exercise when compared with the same exercise performed after a meal. This higher utilisation of fat as an energy source at rest may promote reduction in body fat.

On the basis of these data, aerobic exercise performed in the fasted state has been considered a strategy to increase fat oxidation during exercise and, chronically, to promote adaptations that may be beneficial to health. However, although most studies reported higher fat oxidation under these conditions compared with a carbohydrate-fed state, it is not clear whether the stimulation of lipolytic activity and/or decreased re-esterification of NEFA that occur during the fasted state ${ }^{(20)}$ result in a significantly increased use of fat as an energy substrate during exercise. This systematic review with meta-analysis aimed to verify the effect of aerobic exercise performed during fasted $v$. fed states on fat and carbohydrate metabolism in adults.

\section{Methods}

\section{Eligibility criteria}

This review considered clinical trials (parallel and randomised cross-over designs) evaluating the effect of performing an aerobic exercise intervention of no $>120$ min duration (or data at $120 \mathrm{~min}$ for those interventions with longer durations) in a fasted state among adults aged 19-59 years. These interventions had to be compared with the same exercise performed in the fed state (prior consumption of meals containing at least $25 \mathrm{~g}$ of carbohydrates) ${ }^{(21)}$. Included studies evaluated the following outcome measures: fat oxidation during exercise, considered the primary end point; and serum concentrations of NEFA, glucose and insulin immediately before and after the exercise session; the absolute weighted mean differences of these concentrations were considered the secondary end points. Studies that evaluated these acute responses to aerobic exercise were included; trials that did not present acute outcome data were excluded. In the case of trials with several publications (or sub-studies), the study was included only once.

\section{Search strategy}

The electronic databases MEDLINE ${ }^{\circledR}$ (via PubMed ${ }^{\circledR}$ ), Scopus and Cochrane were used. In addition, manual searches were conducted of references of studies identified for inclusion. The search was conducted in March 2015 and updated in July 2016. The terms 'fasting', 'exercise', 'aerobic exercise', 'substrate', 'energy metabolism', 'fat', 'glucose', 'insulin' and 'adult' as well as related entry terms were used. The searches were limited to articles published in English, Portuguese and Spanish languages. The search strategy used in the PubMed ${ }^{\circledR}$ database is available as the online Supplementary Material. Details of other strategies may be obtained upon request. This systematic review and meta-analysis was prepared and is presented in accordance with 'Preferred Reporting Items for Systematic Reviews and Meta-Analyses' guidelines ${ }^{(22,23)}$.

\section{Selection of studies}

Selection of studies for review was performed independently and duplicated, without restriction on the date of publication. First, the titles and abstracts of all articles identified by the search strategy were evaluated for inclusion independently by two researchers (A. F. V. and L. C.), in duplicate form. Whenever the abstract did not provide sufficient information about inclusion and exclusion criteria, the full article was evaluated. Second, the same reviewers independently evaluated the full articles of those identified as appropriate from the abstract screening process, and made their selection according to eligibility criteria. Disagreements between reviewers were resolved by consensus, and in the case of continuing disagreement the evaluation was made by a third reviewer (R. R. C.). To avoid possible double counting of participants included in more than one report by the same authors/working groups, the periods of recruitment of participants and areas of recruitment were evaluated, and authors were contacted for clarification where necessary.

\section{Data extraction}

Data extraction was performed by two reviewers (A. F. V. and L. C.) independently concerning methodological characteristics, interventions and outcomes of the studies using a standardised form. As in the selection stage, disagreements were resolved by consensus or by a third reviewer (R. R. C.). The extracted data included average age, BMI, sex and training status of participants; exercise duration and intensity; time between dietary intake and the start of exercise; amount of carbohydrate consumed in the pre-exercise meal; and the end points analysed. If the required data were not found in the published report, the corresponding author was contacted to provide missing data and, in the absence of responses or data extraction alternatives, the study or missing end point was excluded from the review. Data presented only graphically, and for which more detail was not provided despite a request to the corresponding authors, were extracted using 'DigitizeIt' software. Where it was not possible to extract means or standard deviations from graphs at the required points, the variable was excluded from the analysis.

In this phase, studies that included diabetic participants, or those in which carbohydrates were provided during exercise as part of the study protocol, were excluded to avoid possible bias in the results. The primary end point we assessed was the total absolute average fat oxidation during exercise. Secondary end points were the weighted mean difference in insulin, glucose and NEFA concentrations. Weighted mean differences were calculated from values taken immediately before and during the last minute of exercise for studies lasting $\leq 120 \mathrm{~min}$. For studies of longer duration, the time ' 120 min' was considered the last minute of exercise.

In studies where the total absolute average fat oxidation during exercise was not presented in the published article, a request was submitted to the authors, and if means for $\mathrm{VO}_{2}$ and carbon dioxide production values were provided these were applied to the formula determined by Péronnet \& Massicotte ${ }^{(24)}$ in order to determine the fat oxidation rate. The units of measurements used in this review were grams for fat oxidation, mmol/l for concentrations of NEFA and glucose, and pmol/l for insulin 
concentrations. Study data not presented in these units were converted. For instance, where fat oxidation was presented using an energy value $(\mathrm{kJ} / \mathrm{kcal})$, these averages were divided by $40.79 \mathrm{~kJ}$ $(9.75 \mathrm{kcal})$ in order to obtain the value in grams ${ }^{(25)}$. If these data were not provided by authors, or if it was not possible to calculate the total oxidised absolute average during exercise, the variable or the study was excluded. Studies with two or more comparison groups with the same population were included with only one comparator, which was selected according to the time between dietary intake and exercise and/or the nutritional characteristics of meals consumed that most closely resembled the other studies being reviewed, in an effort to standardise results. For studies with two or more intervention groups, a single group was also included, selected according to characteristics similar to other studies.

\section{Evaluation of risk of bias}

The assessment of the methodological quality of included studies was performed according to criteria proposed by Cochrane $^{(26)}$ : appropriate use of randomisation sequences, allocation concealment, blinding of participants and/or therapists, blinding of assessors to outcomes, and description of losses and exclusions. When these processes had been described in the published document, it was considered that criteria had been met and these studies were classified as being at 'low risk' of bias and, in opposition, as 'high risk'. Studies that did not report these data were classified as 'unclear risk'. Descriptions of losses and exclusions were considered 'low risk' when the number of participants evaluated were presented in the legends of charts and graphs. Quality evaluation was performed independently by two reviewers (A. F. V. and L. C.).

\section{Data analysis}

Results are presented as weighted mean differences for absolute values between treatments with $95 \%$ CI. The standard deviation of mean difference values not provided by studies was imputed according to the equation proposed by Higgins et al. ${ }^{(27)}$. Statistical heterogeneity of treatment effects between studies was evaluated by Cochran's $Q$ test and $I^{2}$ inconsistency test; values above $50 \%$ indicated high heterogeneity ${ }^{(28)}$. In case of low heterogeneity, the fixed effect model was used to pool study results for the outcomes. When significant heterogeneity was observed $\left(I^{2}>50 \%\right)$, the random effects model was applied. Meta-analyses comprised comparisons of fat oxidation during aerobic exercise performed in the fasted $v$. fed state and the changes in concentrations (expressed using weighted mean differences) of glucose, NEFA and insulin from immediately before exercise to the last minute of exercise (post-exercise). Values of $\alpha \leq 0.05$ were considered statistically significant.

For variables with high heterogeneity, sensitivity analyses were performed according to the following criteria: exercise time, exercise intensity, sex of participants, BMI of participants, training level of participants, pre-exercise values for each variable, time between dietary intake and the start of exercise, and amount of carbohydrate consumed in the pre-exercise meal.

Furthermore, publication bias was assessed using funnel plots for each outcome (of each trial's effect size against the standard error). Funnel plot asymmetry was evaluated using Begg and Egger tests ${ }^{(29)}$, and a significant publication bias was considered if $P<0 \cdot 10$. The trim-and-fill computation was used to estimate the effect of publication bias on the interpretation of results.

All analyses were performed using Comprehensive Meta-Analysis version 2.0, except the risk of bias, which was performed using Review Manager version 5.3 (Cochrane Collaboration).

\section{Results}

\section{Description of studies}

Of the 10405 studies identified from the database searches, twenty-three met our inclusion criteria. An additional four studies were included from a manual search of the reference lists of the included studies, bringing the total number of articles included to twenty-seven. Of these, three studies ${ }^{(30-32)}$ were included twice because they had met eligibility criteria for two groups with different populations, in which each population had a different intervention group and control group: references 'Bergman \& Brooks, 1999a' and 'Montain et al., 1991a' related to populations comprised of trained men, 'Bergman \& Brooks, 1999b' and 'Montain et al., 1991b' related to populations comprised of untrained men, and 'Isacco et al., 2012a' and 'Isacco et al., 2012b' related to populations of women who did not and did use the contraceptive pill, respectively. Thus, thirty comparisons were used in this meta-analysis (Fig. 1). In total, 270 and 269 participants were included in the fasted and fed groups, respectively. The majority of studies (80\%) analysed men, whereas $13.3 \%$ analysed women, and 6.6\% analysed both sexes. Most samples comprised physically active individuals (86.7\%), and exercise sessions lasted an average of $73 \mathrm{~min}$. The meals were provided 30-240 min before the interventions and were composed of a maximum of $215 \mathrm{~g}$ of carbohydrates (Table 1).

In all, four studies were excluded from our analysis: one study was unaccessible ${ }^{(33)}$, and the other three met all eligibility criteria, but were not used because of the unavailability of results ${ }^{(34)}$, or the presentation of averages ${ }^{(19)}$ and standard deviations ${ }^{(35)}$ graphically, with no clarification received from authors and no possibility of data extraction using 'DigitizeIt' software.

From some of the studies included, it was necessary to exclude certain variables because absolute averages were not given - for example, the absolute average of fat oxidation during exercise $^{(6,7,36-38)}$. Other variables were excluded as it was impossible to extract values for standard deviation of insulin ${ }^{(39-42)}$, glucose ${ }^{(40,41,43)}$ and NEFA ${ }^{(32,40)}$ concentrations. These data were all requested from authors but were not provided. 'DigitizeIt' software was used to extract the average relating to fat oxidation from one study ${ }^{(44)}$, relating to NEFA concentrations from fourteen studies ${ }^{(6,7,37,38,41-43,45-51)}$, relating to glucose concentrations from sixteen studies $^{(6,7,32,36-39,42,45-52)}$ and relating to insulin concentrations from thirteen studies ${ }^{(6,7,37,38,43,45-52)}$.

\section{Risk of bias}

Of the included studies, $80 \%$ showed adequate generation of randomisation sequence, $6.6 \%$ reported allocation 


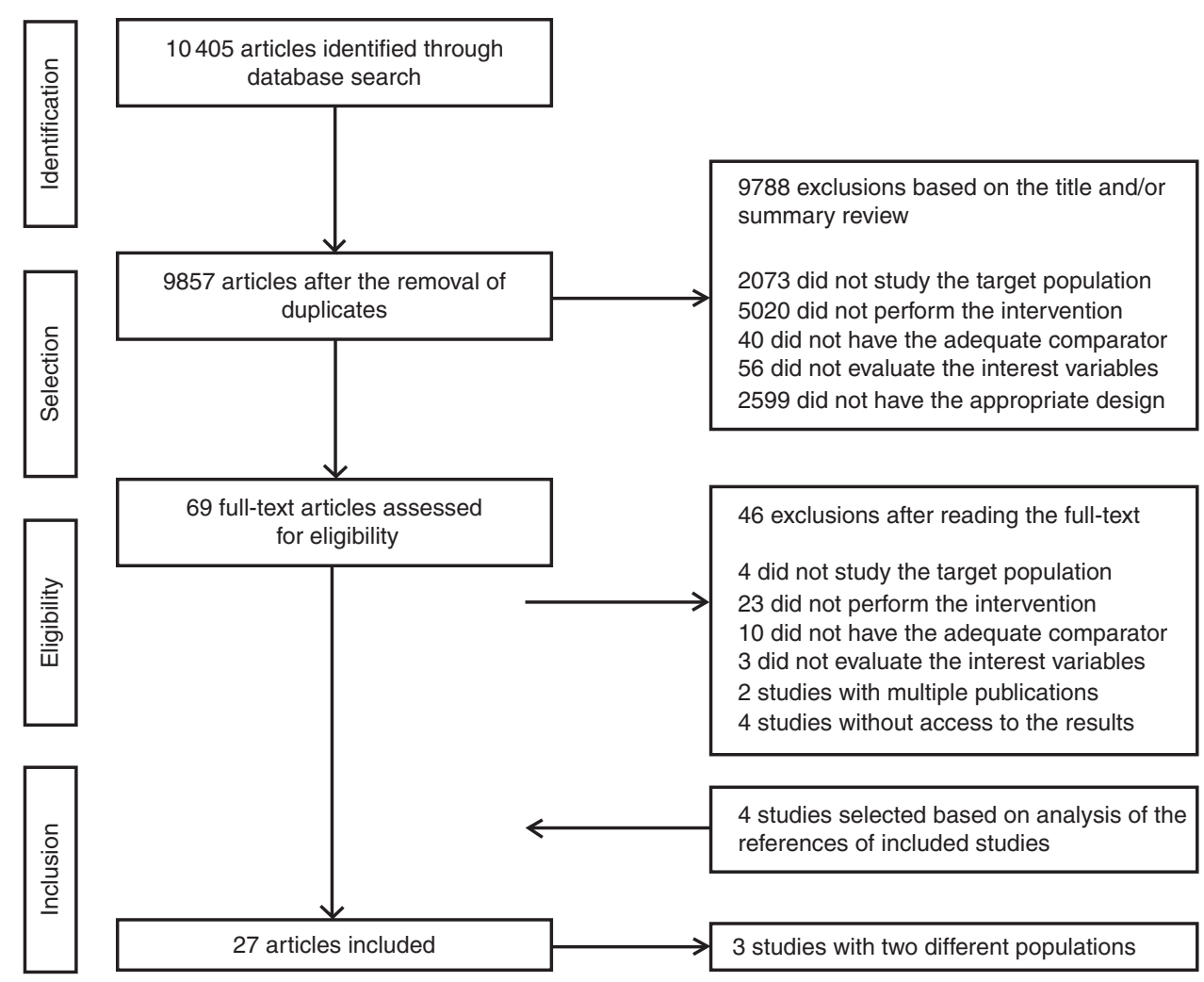

Fig. 1. Flow chart of the included studies.

concealment, $20 \%$ had blinded participants and/or therapists, 6.6\% had blinded the assessors to the outcomes and $66.6 \%$ described losses to follow-up and exclusions (Fig. 2 and 3).

\section{Effects of interventions}

Fat oxidation. Data on fat oxidation were available from eleven studies $^{(30,31,39-41,43,44,47,50-52)}$, with a total of 117 individuals evaluated (Fig. 4). Aerobic exercise performed in the fasted state was associated with a significant increase in fat oxidation during exercise when compared with the fed state (effect size: $-3.53 ; 95 \%$ CI $\left.-4.76,-2.30 ; I^{2} 39.1 \%\right)$. Aerobic exercise performed in the fasted state led to an increase in fat oxidation of approximately $3.53 \mathrm{~g}$, compared with execution of the same exercise after consumption of meals containing carbohydrates. However, the analysis of publication bias identified a significant bias $(P=0.007)$, and thus the adjusted value of the effect size, according to the Duval \& Tweedie's trim and fill test, resulted in $3.08 \mathrm{~g}$.

Given the influence of exercise intensity on fat oxidation, sensitivity analyses were performed to identify whether there was an effect difference when stratified by two different intensity ratings $-\mathrm{VO}_{2 \max }<70 \%$ and $\mathrm{VO}_{2 \max } \geq 70 \%$. Thus, even though the meta-analysis did not demonstrate significant heterogeneity $(P=0.07)$, sensitivity analyses were performed: $<70 \% \mathrm{VO}_{2 \max }\left(3.45 \mathrm{~g} ; 95 \% \mathrm{CI} 2 \cdot 19,4.71 ; P<0.001 ; I^{2} 50 \%\right)$ and $\geq 70 \% \mathrm{VO}_{2 \max }\left(5 \cdot 38 \mathrm{~g} ; 95 \% \mathrm{CI}-0.45,11 \cdot 21 ; P=0.07 ; I^{2} 0 \%\right)$. Aerobic exercise of low-to-moderate intensity performed in the fasted state induced a higher fat oxidation compared with a fed state. On the other hand, there was no significant difference between fasted and fed states in relation to fat oxidation during aerobic exercise of moderate-to-high intensity.

Sensitivity analyses were also performed for fat oxidation taking the following into account: exercise time $(\leq 60 \mathrm{~min}$ : $3.35 \mathrm{~g} ; 95 \%$ CI 2.07, 4.62; $P<0.001 ; I^{2} 54 \%$; >60 min: $6.13 \mathrm{~g}$; $95 \%$ CI $1.37,10 \cdot 88 ; P=0 \cdot 01 ; I^{2} 9 \%$ ); sex of participants (male: $6.39 \mathrm{~g} ; 95 \%$ CI 3.84, 8.94; $P<0.001 ; I^{2} 0 \%$; female: $2.60 \mathrm{~g}$; $95 \%$ CI $\left.1.19,4.01 ; P=0.0003 ; I^{2} 0 \%\right) ;$ BMI of participants $\left(<25 \mathrm{~kg} / \mathrm{m}^{2}: 2.79 \mathrm{~g} ; 95 \%\right.$ CI $\left.1.42,4.17 ; P<0.001 ; I^{2} 30 \%\right)$; training level of participants (physically active: $3.74 \mathrm{~g}$; $95 \% \mathrm{CI}$ 1.97, 5.52; $P<0.001 ; I^{2} 49 \%$; sedentary: $3.34 \mathrm{~g} ; 95 \%$ CI 1.62 , 5.05; $P=0.0001 ; I^{2} 23 \%$ ); time between consumption of meal and the beginning of exercise ( $<100 \mathrm{~min}$ : $3.41 \mathrm{~g}$; $95 \%$ CI 1.68 , 5.14; $P=0.0001 ; I^{2} 57 \%$; $>100$ min: 3.66 g; $95 \%$ CI $1.91,5.41$; $\left.P<0.001 ; I^{2} 37 \%\right)$; and quantity of carbohydrate consumed in the pre-exercise meal $(<100 \mathrm{~g}: 3.51 \mathrm{~g} ; 95 \%$ CI 1.84, 5.17; $P<0.001 ; I^{2} 34 \%$; $\geq 100$ g: 3.56 g; $95 \%$ CI $1.73,5.39 ; P=0.0001$; $\left.I^{2} 53 \%\right)$. Thereby, these results demonstrated no change in the pattern already presented, of higher fat oxidation when the exercise is performed in the fasted state, regardless of the adopted criteria for the sensitivity analyses.

NEFA. Data on NEFA concentrations were available from sixteen studies ${ }^{(6,7,31,37,38,41-43,45-52)}$, with a total of 144 individuals evaluated (Fig. 5). All but one of these studies used the same sample populations for both interventions ${ }^{(37)}$. The weighted mean difference of NEFA before and after exercise 
Table 1. Characteristics of included studies (Mean values and standard deviations) ${ }^{\star}$

\begin{tabular}{|c|c|c|c|c|c|c|c|c|}
\hline \multirow[b]{2}{*}{ Studies } & \multicolumn{2}{|c|}{ Age (years) } & \multirow[b]{2}{*}{ Sex/n } & \multirow[b]{2}{*}{ Training status } & \multirow{2}{*}{$\begin{array}{l}\text { Exercise duration } \\
\text { (min) }\end{array}$} & \multirow[b]{2}{*}{ Exercise intensity } & \multirow{2}{*}{$\begin{array}{l}\text { Time between meal } \\
\text { and exercise ( } \mathrm{min})\end{array}$} & \multirow{2}{*}{$\begin{array}{l}\text { Amount of carbohydrate } \\
\text { pre exercise meal }(\mathrm{g})\end{array}$} \\
\hline & Mean & SD & & & & & & \\
\hline Aziz et al. ${ }^{(53)}$ & $27 \cdot 3$ & $7 \cdot 2$ & Male/10 & Physically active & 60 & $65.0 \% \mathrm{VO}_{2 \max }$ & 180 to 240 & $126 \cdot 7$ \\
\hline Bergman \& Brooks ${ }^{(30)}$ & $25 \cdot 1$ & 4.8 & Male/7 & Physically active & 90 & $60.0 \% \mathrm{VO}_{2 \text { peak }}$ & 180 & $119 \cdot 6$ \\
\hline Bergman \& Brooks ${ }^{(30)}$ & $22 \cdot 1$ & 3.4 & Male/7 & Sedentary & 120 & $40.0 \% \mathrm{VO}_{2 \text { peak }}$ & 180 & 119.6 \\
\hline Bouhlel et al. ${ }^{(5)}$ & $19 \cdot 0$ & $2 \cdot 0$ & Male/9 & Physically active & 30 & $20 \cdot 0,30 \cdot 0,40 \cdot 0,50 \cdot 0,60.0 \% W_{\max }$ & Does not mention & Does not mention \\
\hline Coyle et al. ${ }^{(45)}$ & $25 \cdot 0$ & $5 \cdot 0$ & Male/7 & Physically active & 105 & $70.0 \% \mathrm{VO}_{2 \max }$ & 240 & 141.8 \\
\hline Coyle et al. ${ }^{(7)}$ & $22 \cdot 0$ & 4.9 & Male/6 & Physically active & 40 & $50.0 \% \mathrm{VO}_{2 \max }$ & 60 and 10 & 96.6 \\
\hline Dohm et al. ${ }^{(46)}$ & $28 \cdot 7$ & 3.9 & Male/9 & Physically active & $\begin{array}{c}90 \text { or until exhaustion } \\
\text { (about } 80 \text { ) }\end{array}$ & $70 \cdot 0-75.0 \% \mathrm{VO}_{2 \max }$ & 120 to 240 & $47 \cdot 0$ \\
\hline Farah \& Gill ${ }^{(39)}$ & $28 \cdot 1$ & $10 \cdot 7$ & Male/10 & Sedentary & 60 & $50.0 \% \mathrm{VO}_{2 \max }$ & 30 & $56 \cdot 5$ \\
\hline Gonzalez et al. ${ }^{(47)}$ & $23 \cdot 2$ & $4 \cdot 3$ & Male/12 & Physically active & 59 & $61 \cdot 1 \% \mathrm{VO}_{2 \text { peak }}$ & 120 & $66 \cdot 6$ \\
\hline Guéye et al. ${ }^{(55)}$ & 22.5 & 1.7 & Male/12 & Physically active & 60 & $75.0 \% \mathrm{HR}_{\max }$ & Does not mention & Does not mention \\
\hline Horowitz et al. ${ }^{(6)}$ & $26 \cdot 5$ & $9 \cdot 3$ & Male/6 & Physically active & 60 & $44.0 \% \mathrm{VO}_{2 \text { peak }}$ & 60 & $60 \cdot 0$ \\
\hline Isacco et al. ${ }^{(31)}$ & $22 \cdot 9$ & 3.6 & Female/10 & Sedentary & 45 & $65.0 \% \mathrm{VO}_{2 \max }$ & 180 & $72 \cdot 2$ \\
\hline Isacco et al. ${ }^{(31)}$ & $21 \cdot 2$ & 1.9 & Female/11 & Sedentary & 45 & $65.0 \% \mathrm{VO}_{2 \max }$ & 180 & 73.4 \\
\hline Kirwan et al. ${ }^{(48)}$ & $22 \cdot 0$ & $2 \cdot 4$ & Male/6 & Physically active & Until exhaustion (120) & $60.0 \% \mathrm{VO}_{2 \text { peak }}$ & 45 & $75 \cdot 0$ \\
\hline Kirwan et al. ${ }^{(49)}$ & 24.0 & 4.9 & Female/6 & Physically active & Until exhaustion (120) & $60.0 \% \mathrm{VO}_{2 \text { peak }}$ & 45 & $75 \cdot 0$ \\
\hline Little et al. ${ }^{(36)}$ & $23 \cdot 3$ & 3.8 & Male/7 & Physically active & $90(45)$ & $V_{\max }$ & 180 & 86.0 \\
\hline Little et al. ${ }^{(50)}$ & $22 \cdot 8$ & $3 \cdot 2$ & Male/13 & Physically active & 105 & $V_{\max }$ & 120 & Does not mention $(1.5 \mathrm{~g} / \mathrm{kg})$ \\
\hline Massicotte et al. ${ }^{(52)}$ & $\begin{array}{l}24 \cdot 8(S D \\
22 \cdot 1(S D\end{array}$ & $\begin{array}{l}\text { 9) (fast) } \\
\text { 3) (fed) }\end{array}$ & Male/5 & Physically active & $120(60)$ & $52.0 \% \mathrm{VO}_{2 \max }$ & 180 & 50.0 \\
\hline $\begin{array}{l}\text { Maughan \& } \\
\text { Gleeson }^{(40)}\end{array}$ & $34 \cdot 0$ & 8.9 & Male/5 & Physically active & Until exhaustion (90) & $70.0 \% \mathrm{VO}_{2 \max }$ & 45 & $69 \cdot 8$ \\
\hline Montain et al. ${ }^{(32)}$ & Does nc & lention & Male/9 & Physically active & 30 & $70.0 \% \mathrm{VO}_{2 \text { peak }}$ & 120 & 131.6 \\
\hline Montain et al. ${ }^{(32)}$ & Does nc & lention & Male/8 & Physically active & 30 & $70.0 \% \mathrm{VO}_{2 \text { peak }}$ & 120 & 154.6 \\
\hline Paul et al. ${ }^{(41)}$ & 24.9 & 3.4 & Mixed/12 & Physically active & 90 & $60.0 \% \mathrm{VO}_{2 \text { peak }}$ & 90 & 32.4 \\
\hline $\begin{array}{l}\text { Ramos-Jiménez } \\
\text { et al. }{ }^{(56)}\end{array}$ & $22 \cdot 5$ & 3.7 & Mixed/30 & Physically active & 8 to 15 & $98.0 \% \mathrm{HR}_{\max }$ & 70 & $\begin{array}{l}\text { Does not mention } \\
\text { (60\% ETV meal) }\end{array}$ \\
\hline Satabin et al. ${ }^{(42)}$ & $25 \cdot 2$ & $17 \cdot 7$ & Male/9 & Physically active & 110 & $60.0 \% \mathrm{VO}_{2 \max }$ & 60 & $100 \cdot 0$ \\
\hline Schabort et al. ${ }^{(37)}$ & $26 \cdot 0$ & 7.9 & Male/7 & Physically active & 105 & $70.0 \% \mathrm{VO}_{2 \max }$ & 180 & $100 \cdot 0$ \\
\hline Shin et al. ${ }^{(38)}$ & $23 \cdot 3$ & $2 \cdot 5$ & Male/8 & Physically active & 60 & $50.0 \% \mathrm{VO}_{2 \max }$ & 30 & $66 \cdot 4$ \\
\hline Whitley et al. ${ }^{(43)}$ & $21 \cdot 0$ & 10.8 & Male/8 & Physically active & 90 & $70.0 \% \mathrm{VO}_{2 \max }$ & 240 & $215 \cdot 0$ \\
\hline Willcutts et al. ${ }^{(44)}$ & $23 \cdot 7$ & $2 \cdot 4$ & Female/8 & Physically active & $30(23)$ & $62.0 \% \mathrm{VO}_{2 \max }$ & 90 & $109 \cdot 3$ \\
\hline Wu et al. ${ }^{(51)}$ & $26 \cdot 8$ & $3 \cdot 3$ & Male/9 & Physically active & 60 & $65.0 \% \mathrm{VO}_{2 \max }$ & 180 & $141 \cdot 0$ \\
\hline Ziogas \& Thomas ${ }^{(57)}$ & $27 \cdot 4$ & 3.8 & Male/7 & Physically active & 60 & $60.0 \% \mathrm{VO}_{2 \max }$ & 180 & 111.5 \\
\hline
\end{tabular}

$\mathrm{VO}_{2 \text { peak, }}$ peak $\mathrm{VO}_{2} ; W_{\text {max }}$, maximum power; $\mathrm{HR}_{\text {max }}$, maximum heart rate; $V_{\text {max }}$, maximum velocity; $\mathrm{ETV}$, energy total value.

* Exercise duration: total time of exercise duration evaluated in the study (time post exercise extracted). 


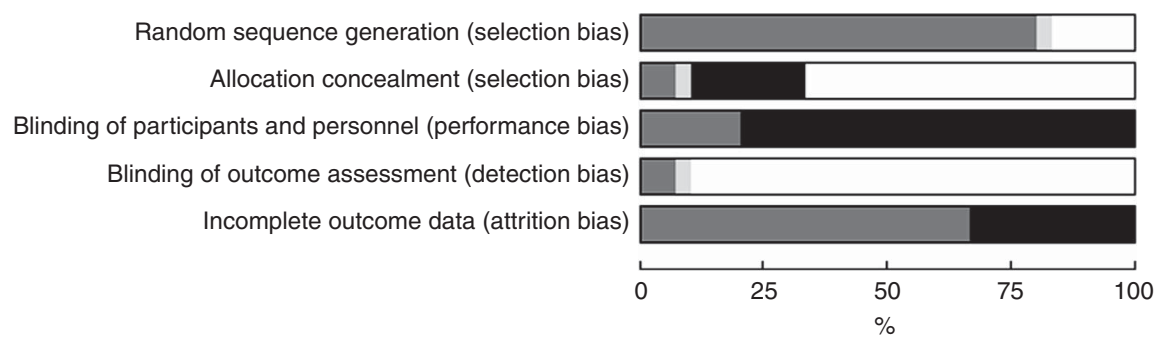

Fig. 2. Risk of bias in the included studies. $\square$, Low risk of bias; $\square$, unclear risk of bias; $\square$, high risk of bias.

was not demonstrated to be significantly different between exercise performed in the fasted or fed states (effect size: 0.00; $95 \%$ CI $\left.-0.07,0.08 ; I^{2} 72.7 \%\right)$. The analysis of publication bias for this outcome showed no significant bias $(P=0 \cdot 124)$.

Owing to the high heterogeneity $(P<0.001)$ found in the analysis of this variable, sensitivity analyses were performed. Significant heterogeneity was found for most of the variables analysed: exercise time ( $\leq 60 \mathrm{~min}: I^{2} 93 \%$; $P<0.001$; $>60 \mathrm{~min}$ : $I^{2} 83 \%$; $P<0.001$ ); exercise intensity (<70\% $\mathrm{VO}_{2 \max }: I^{2} 92 \%$; $\left.P<0.001 ; \geq 70 \% \mathrm{VO}_{2 \text { max }}: I^{2} 74 \% ; P=0.004\right)$; sex of participants (male: $I^{2} 90 \%$; $P<0.001$; female: $I^{2} 90 \% ; P<0.001$ ); BMI of participants $\left(<25 \mathrm{~kg} / \mathrm{m}^{2}: I^{2} 90 \% ; P<0.001 ;>25 \mathrm{~kg} / \mathrm{m}^{2}: I^{2} 0 \%\right.$; $P=0.76$ ); training level of participants (physically active: $I^{2}$ 90\%; $P<0.001$; sedentary: $\left.I^{2} 0 \% ; P=0.65\right)$; pre-exercise values for fasting ( $\left.<1 \mathrm{mmol} / \mathrm{l}: I^{2} 90 \% ; P<0.001\right)$; time between consumption of meal and the beginning of exercise $(<100 \mathrm{~min}$ : $\left.I^{2} 85 \% ; P<0.001 ;>100 \mathrm{~min}: I^{2} 82 \% ; P<0.001\right)$; and quantity of carbohydrate consumed in the pre-exercise meal $(<100 \mathrm{~g}$ : $I^{2} 87 \% ; P<0.001 ; \geq 100$ g: $\left.I^{2} 90 \% ; P<0.001\right)$. Sensitivity analyses for the criterion 'pre-exercise values in fasting $>1 \mathrm{mmol} / \mathrm{l}$ ' were not performed because only one study presented this characteristic. The criteria 'BMI $>25 \mathrm{~kg} / \mathrm{m}^{2}$ ' and 'sedentary' showed no significant heterogeneity, although sensitivity analyses were performed with only two studies for each. Owing to the maintenance of high heterogeneity and/or low number of studies, the data presented graphically (Fig. 5) refer to the general analysis (disregarding the sensitivity analysis).

Glucose. Data on glucose concentrations were available from twenty-two studies ${ }^{(6,7,31,32,36-39,42,45-57)}$, with a total of 226 individuals evaluated (Fig. 6). All but one of these studies used the same sample populations for both interventions ${ }^{(37)}$. Significantly lower variation was reported for glucose concentrations from before to after exercise in the fasted $v$. fed states (effect size: 0.60; 95\% CI 0.25, 0.94; I ${ }^{2}$ 90.8\%). Nevertheless, the analysis of publication bias identified a significant bias $(P=0.057)$, and thus the adjusted value of the effect size, according to the Duval \& Tweedie's trim-and-fill test, resulted in $0.78 \mathrm{mmol} / \mathrm{l}$

Because of the high heterogeneity $(P=0.001)$ found for this variable, sensitivity analyses were performed and, again, significant heterogeneity was found in most analyses. These variables were as follows: exercise time ( $\leq 60 \mathrm{~min}: I^{2} 95 \%$; $P<0.001 ;>60$ min: $I^{2}$ 99\%; $\left.P<0.001\right)$; exercise intensity $\left(<70 \% \mathrm{VO}_{2 \max }: I^{2} 98 \% ; P<0.001 ; \geq 70 \% \mathrm{VO}_{2 \max }: I^{2} 80 \%\right.$;
$P<0.001$ ); sex of participants (male: $I^{2} 95 \%$; $P<0 \cdot 001$; female: $I^{2}$ 99\%; $\left.P<0.001\right)$; BMI of participants $\left(<25 \mathrm{~kg} / \mathrm{m}^{2}: I^{2} 99 \%\right.$; $\left.P<0.001 ;>25 \mathrm{~kg} / \mathrm{m}^{2}: I^{2} 82 \% ; P=0.001\right)$; training level of participants (physically active: $I^{2} 97 \% ; P<0.001$; sedentary: $\left.I^{2} 16 \% ; P=0.30\right)$; pre-exercise values in fasting $(<5 \mathrm{mmol} / \mathrm{l}$ : $I^{2} 95 \%$; $P<0.001 ;>5 \mathrm{mmol} / \mathrm{l}: I^{2} 99 \%$; $\left.P<0.001\right)$; time between consumption of meal and the beginning of exercise $(<100 \mathrm{~min}$ : $I^{2} 98 \% ; P<0.001$; $>100$ min: $\left.I^{2} 69 \% ; P<0.001\right)$; and quantity of carbohydrate consumed in the pre-exercise meal $(<100 \mathrm{~g}$ : $I^{2} 98 \% ; P<0.001 ; \geq 100$ g: $\left.I^{2} 44 \% ; P=0 \cdot 08\right)$. Again, the criterion 'sedentary' showed no significant heterogeneity, although the sensitivity analysis was performed with only two studies. The criterion 'quantity of carbohydrate consumed in the preexercise meal $\geq 100$ g' was analysed with eight interventions ( $n$ 66), and did not show significant heterogeneity. Therefore, in this case, the weighted mean difference of relative glucose concentrations did not appear to differ significantly when exercise was performed in a fasted $v$. fed state $(P=0.91)$. Because of the high heterogeneity and/or low number of studies, the data presented graphically (Fig. 6) refer to the general analysis (disregarding the sensitivity analysis). More detailed results of the sensitivity analysis performed for this variable relating to the criterion 'quantity of carbohydrate consumed in the pre-exercise meal $\geq 100$ g' can be provided on request.

Insulin. Data on insulin concentrations were available from fifteen studies ${ }^{(6,7,31,32,37,38,43,45-52)}$, with a total of 140 individuals evaluated (Fig. 7). Again, all but one of these studies used the same sample populations for both interventions ${ }^{(37)}$. Significantly lower variation was reported for insulin concentrations from before to after exercise in the fasted $v$. fed states (effect size: 104.5; $95 \%$ CI 70.8, 138.2; $I^{2} 92.5 \%$ ). However, the analysis of publication bias identified a significant bias $(P<0.001)$, and thus the adjusted value of the effect size, according to the Duval \& Tweedie's trim and fill test, resulted in $104.5 \mathrm{pmol} / 1$.

As with the other blood variables, high heterogeneity was found $(P<0 \cdot 001)$ and sensitivity analyses were consequently performed. Once again, significant heterogeneity was found for most comparisons: exercise time ( $\leq 60 \mathrm{~min}: I^{2} 82 \% ; P<0.001$; $>60$ min: $I^{2} 95 \%$; $\left.P<0.001\right)$; exercise intensity ( $<70 \% \mathrm{VO}_{2 \max }$ : $I^{2} 91 \%$; $P<0.001$; $\geq 70 \% \mathrm{VO}_{2 \max }: I^{2} 89 \%$; $\left.P<0.001\right)$; sex of participants (male: $I^{2}$ 93\%; $P<0.001$; female: $I^{2} \quad 96 \%$; $P<0.001)$; BMI of participants $\left(<25 \mathrm{~kg} / \mathrm{m}^{2}: I^{2} 90 \% ; P<0.001\right.$; $\left.>25 \mathrm{~kg} / \mathrm{m}^{2}: I^{2} 98 \% ; P<0.001\right)$; training level of participants 


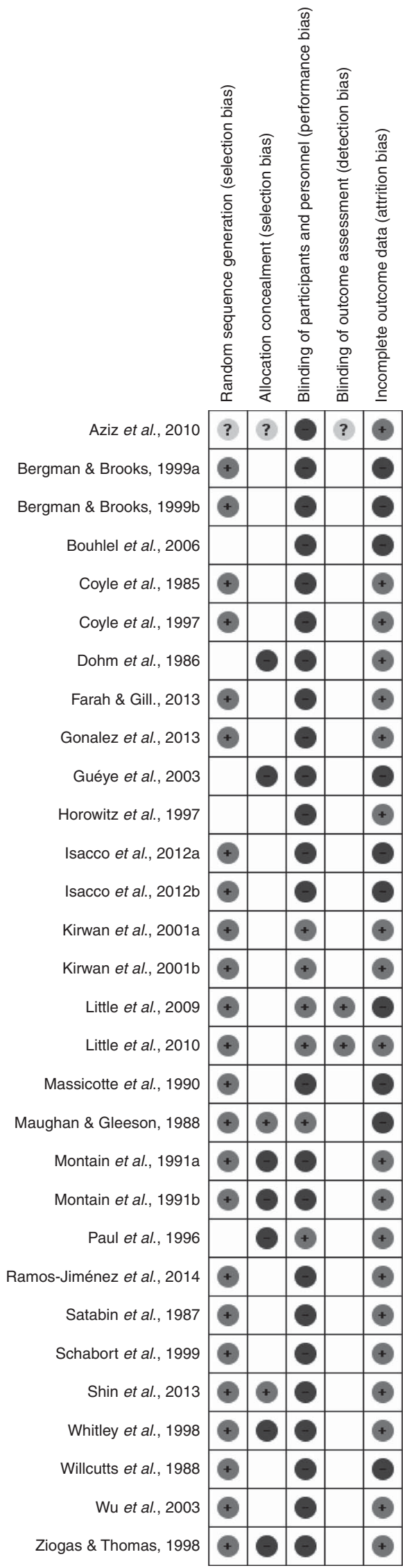

Fig. 3. Summary of risk of bias in the included studies. (physically active: $I^{2} \quad 95 \% ; \quad P<0.001 ;$ sedentary: $I^{2} \quad 0 \%$; $P=0.39)$; pre-exercise values in the fed state $(<200 \mathrm{pmol} / \mathrm{l}$ : $I^{2} 92 \% ; P<0.001$; $>200 \mathrm{pmol} / \mathrm{l}: I^{2} 83 \%$; $\left.P<0.001\right)$; time between consumption of meal and the beginning of exercise $(<100 \mathrm{~min}$ : $I^{2} 95 \%$; $P<0.001$; $>100$ min: $\left.I^{2} 91 \% ; P<0.001\right)$; and quantity of carbohydrate consumed in the pre-exercise meal $(<100 \mathrm{~g}$ : $I^{2} 91 \%$; $P<0.001 ; \geq 100 \mathrm{~g}: I^{2} 92 \%$; $\left.P<0.001\right)$. Once again, the variable 'sedentary' showed no significant heterogeneity, although the sensitivity analysis was performed with only two interventions. Owing to the high heterogeneity and/or low number of studies, the data presented graphically (Fig. 7) refer to the general analysis (disregarding the sensitivity analysis).

\section{Discussion}

The major finding of this systematic review with meta-analysis is that performing aerobic exercise at low-to-moderate intensity in the fasted state induces a significant increase $(3.08 \mathrm{~g})$ in fat oxidation while exercise is being performed. No difference was seen in the variation of NEFA concentrations between exercise performed in the fasted $v$. fed states. However, greater variations in glucose and insulin concentrations were seen when exercise was performed in a fed state.

Carbohydrates and fats are the most important sources of fuel during rest and exercise ${ }^{(4)}$. In general, the lipolytic activity of adipose tissue is regulated by the balance between stimulating hormones such as catecholamines and those that inhibit the enzyme responsible for lipolysis (lipase sensitive hormone), especially insulin ${ }^{(58)}$. Because of higher muscular energy exigency and increased availability of $\mathrm{NEFA}^{(58)}$, mediated by increased adrenergic stimulation ${ }^{(59)}$, exercise alone can increase fat oxidation compared with rest ${ }^{(39)}$.

Among the primary responses to fasting are the partial mobilisation of TAG reserves contained in the adipose tissue and the decreased re-esterification of NEFA. This leads to an increase in the concentration of circulating NEFA in plasma and, consequently, greater availability of this fuel source for the muscles ${ }^{(2,20)}$. These fundamental principles can explain the findings of the present study, suggesting that when exercise is performed in the fasted state, lipolytic activity is increased further because of the action of lipolysis-stimulating hormones and limited action of insulin. However, increased plasma concentrations of NEFA during exercise are attenuated by carbohydrate intake before exercise, due to the inhibition of lipolysis mediated by insulin ${ }^{(6)}$. It has also been suggested that increases in insulin concentrations can directly inhibit the transfer of fat through the muscle cell membrane and/or mitochondrial membranes ${ }^{(8)}$. Therefore, as a consequence of lower availability of NEFA and the inhibition of oxidation of IMTG, exercise performed in the fed state shows reduced fat oxidation ${ }^{(7)}$.

Apart from diet, use of energy substrates during exercise depends on factors such as intensity, duration and level of training ${ }^{(4)}$. It has been shown that fat oxidation, rather than the use of carbohydrate as a substrate, tends to be higher at lowto-moderate intensities of exercise, no $>60-65 \% \mathrm{VO}_{2 \max }$, but is likely to decrease at an intensity $>75 \% \mathrm{VO}_{2 \max }(60,61)$. These data corroborate the findings of the present study, in which most of the interventions relating to fat oxidation during exercise 
Study name

$\begin{array}{lc}\text { Bergman \& Brooks, 1999a } & \begin{array}{c}\text { Difference } \\ \text { in means }\end{array} \\ \text { Bergman \& Brooks, 1999b } & -7 \cdot 87 \\ \text { Farah \& Gill, 2013 } & -5 \cdot 49 \\ \text { Gonzalez et al., 2013 } & -6 \cdot 00 \\ \text { Isacco et al., 2012a } & -4 \cdot 59 \\ \text { Isacco et al., 2012b } & -1 \cdot 74 \\ \text { Little et al., 2010 } & -5 \cdot 15 \\ \text { Massicotte et al., 1990 } & -5 \cdot 00 \\ \text { Maughan \& Gleeson, 1988 } & -0.90 \\ \text { Paul et al., 1996 } & -41.40 \\ \text { Whitley et al., 1998 } & -14 \cdot 38 \\ \text { Willcutts et al., 1988 } & -2 \cdot 62 \\ \text { Wu et al., 2003 } & -18 \cdot 10 \\ & -3.53\end{array}$

Statistics for each study

\begin{tabular}{|c|c|c|c|c|c|}
\hline SE & Variance & $\begin{array}{l}\text { Lower } \\
\text { limit }\end{array}$ & $\begin{array}{l}\text { Upper } \\
\text { limit }\end{array}$ & $Z$-value & $P$ \\
\hline 65 & 58.57 & $-22 \cdot 87$ & $7 \cdot 13$ & -1.03 & 0.304 \\
\hline 24 & $27 \cdot 46$ & -14.76 & $5 \cdot 78$ & -0.86 & 0.391 \\
\hline 1.84 & 3.38 & $-9 \cdot 30$ & $-2 \cdot 10$ & $-3 \cdot 10$ & 0.002 \\
\hline .46 & $19 \cdot 86$ & $-14 \cdot 74$ & $2 \cdot 74$ & -1.35 & 0.178 \\
\hline 1.86 & 3.48 & -8.24 & -0.94 & $-2 \cdot 46$ & 0.014 \\
\hline 1.20 & 1.45 & $-4 \cdot 10$ & 0.62 & $-1 \cdot 45$ & 0.148 \\
\hline 3.43 & 11.74 & -11.87 & 1.57 & $-1 \cdot 50$ & 0.133 \\
\hline .99 & 24.99 & $-14 \cdot 80$ & 4.80 & $-1 \cdot 00$ & 0.317 \\
\hline 63 & $58 \cdot 27$ & $-15 \cdot 86$ & $14 \cdot 06$ & -0.12 & 0.906 \\
\hline 54 & $307 \cdot 60$ & $-75 \cdot 78$ & -7.03 & $-2 \cdot 36$ & 0.018 \\
\hline 67 & 93.52 & $-33 \cdot 33$ & 4.57 & -1.49 & 0.137 \\
\hline 1.02 & 1.04 & $-4 \cdot 62$ & -0.62 & -2.57 & 0.010 \\
\hline $5 \cdot 16$ & $26 \cdot 65$ & $-28 \cdot 22$ & -7.98 & -3.51 & 0.000 \\
\hline 63 & 0.40 & $-4 \cdot 76$ & $-2 \cdot 30$ & $-5 \cdot 62$ & 0.000 \\
\hline
\end{tabular}

Difference in means and $95 \% \mathrm{Cl}$

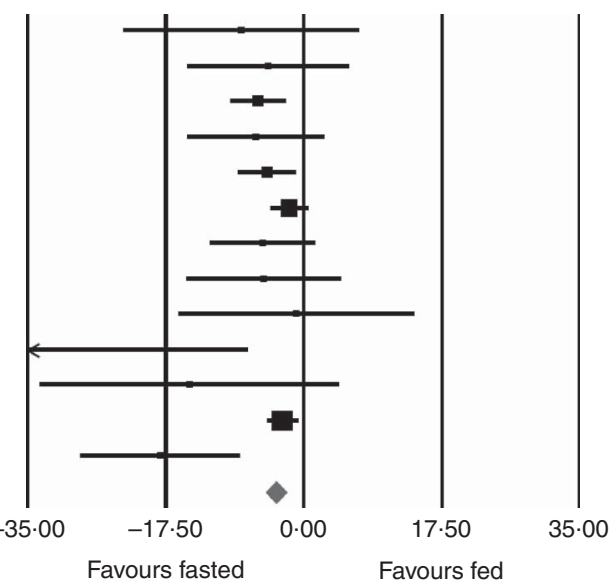

Fig. 4. Fat oxidation (g) during exercise performed in the fasted state $v$. fed state. $\square$, Study-specific estimates: $\bullet$, pooled estimates of fixed-effects meta-analyses.

Study name

Coyle et al., 1985

Coyle et al., 1997

Dohm et al., 1986

Gonzalez et al., 2013

Horowitz et al., 1997

Isacco et al., 2012a

Isacco et al., 2012b

Kirwan et al., 2001a

Kirwan et al., 2001b

Little et al., 2010

Massicotte et al., 1990

Paul et al., 1996

Satabin et al., 1987

Schabort et al., 1999

Shin et al., 2013

Whitley et al., 1998

Wu et al., 2003
Statistics for each study

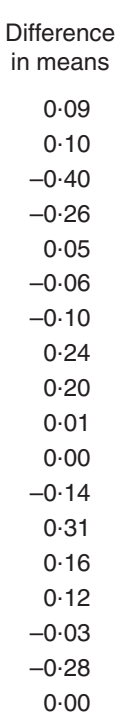

Lower Upper

SE Variance limit limit

0.07

0.03

0.17

0.11

0.05

0.09

0.09

0.10

0.09

0.09

0.35

0.08

0.21

0.30

0.03

0.15

0.08

0.04 $\begin{array}{lll}0.00 & -0.04 & 0.22\end{array}$

$\begin{array}{lll}0.00 & 0.04 & 0.17\end{array}$

$\begin{array}{lll}0.03 & -0.72 & -0.08\end{array}$

$\begin{array}{lll}0.01 & -0.47 & -0.05\end{array}$

$\begin{array}{lll}0.00 & -0.04 & 0.14\end{array}$

$\begin{array}{lll}0.01 & -0.23 & 0.11\end{array}$

$\begin{array}{lll}0.01 & -0.28 & 0.08\end{array}$

$\begin{array}{lll}0.01 & 0.05 & 0.43\end{array}$

$\begin{array}{lll}0.01 & 0.03 & 0.37\end{array}$

$\begin{array}{lll}0.01 & -0.16 & 0.18\end{array}$

$\begin{array}{lll}0.12 & -0.68 & 0.68\end{array}$

$\begin{array}{lll}0.01 & -0.30 & 0.02\end{array}$

$\begin{array}{lll}0.04 & -0.09 & 0.71\end{array}$

$\begin{array}{lll}0.09 & -0.44 & 0.76\end{array}$

$\begin{array}{lll}0.00 & 0.05 & 0.19\end{array}$

$\begin{array}{lll}0.02 & -0.33 & 0.27\end{array}$

$\begin{array}{lll}0.01 & -0.44 & -0.12\end{array}$

$0.00 \quad-0.07 \quad 0.08$

$\begin{array}{rc}\text { Z-value } & P \\ 1.39 & 0.165 \\ 3.01 & 0.003 \\ -2.42 & 0.015 \\ -2.47 & 0.013 \\ 1.12 & 0.264 \\ -0.70 & 0.484 \\ -1.11 & 0.265 \\ 2.53 & 0.011 \\ 2.34 & 0.019 \\ 0.12 & 0.908 \\ 0.00 & 1.000 \\ -1.68 & 0.093 \\ 1.50 & 0.133 \\ 0.53 & 0.598 \\ 3.52 & 0.000 \\ -0.20 & 0.844 \\ -3.48 & 0.001 \\ 0.05 & 0.957\end{array}$

$0.05 \quad 0.957$
Difference in means and $95 \% \mathrm{Cl}$

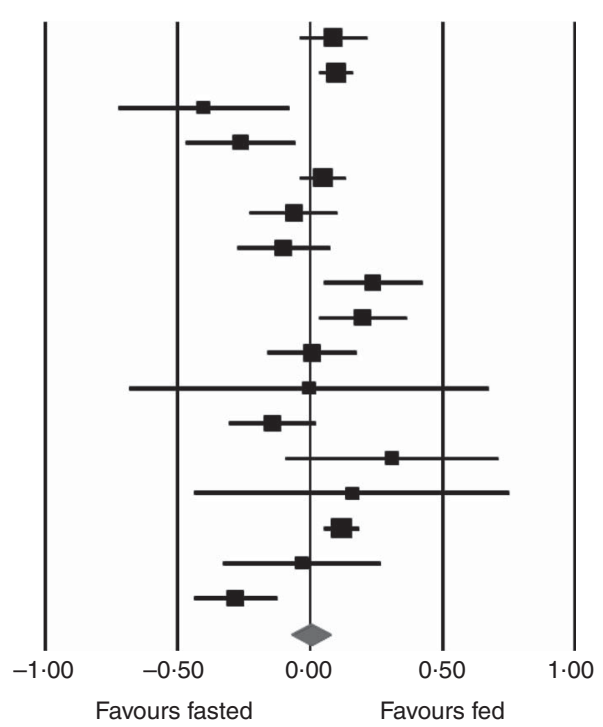

Fig. 5. Weighted mean difference of NEFA concentrations $(\mathrm{mmol} / \mathrm{l})$ relative to exercise performed in the fasted state $v$. fed state. $\diamond$, pooled estimates of random-effects meta-analyses.

included in the meta-analysis were performed with intensities between 40 and $65 \% \mathrm{VO}_{2 \max }(30,31,39,41,44,47,51,52)$. Studies that used greater intensities, and where exact values were given in the published report, did not surpass $70 \% \mathrm{VO}_{2 \max }{ }^{(40,43)}$. Concerning the duration of exercise, the studies included were evaluated up to $120 \mathrm{~min}$. It is suggested that after $2 \mathrm{~h}$ of exercising, the substrate utilisation patterns become similar between fasted and fed states ${ }^{(45)}$. That is, an increase in fat oxidation may also occur in 'fed state' individuals after a certain interval, and may be caused by a reduction in muscle glycogen that occurs in the advanced stages of prolonged exercise ${ }^{(4)}$. Furthermore, the majority of included studies were conducted with physically active individuals $(30,40,41,43,44,47,50-52)$, and the literature indicates that fat oxidation during sub-maximal exercise is improved with aerobic physical training ${ }^{(14,60)}$.

As exercise intensity can influence the utilisation of energy substrates during exercise, sensitivity analyses were performed according to this criterion. It is well established in the literature that the contribution of carbohydrate to energy supply increases incrementally with exercise intensity (>65\% $\left.\mathrm{VO}_{2 \max }\right)$, whereas the fat oxidation peak occurs at lower intensities $\left(45-65 \% \mathrm{VO}_{2 \max }\right.$ ), which may be influenced by sex, training status, $\mathrm{VO}_{2 \max }$ and $\operatorname{diet}^{(60)}$. The present analysis showed that during exercises at intensities $<70 \% \mathrm{VO}_{2 \max }$, fat oxidation was higher in the fasted state (approximately $3.45 \mathrm{~g}$ ), but that there was no difference in this variable between 
Study name

Aziz et al., 2010

Bouhlel et al., 2006

Coyle et al., 1985

Coyle et al., 1997

Dohm et al., 1986

Farah \& Gill, 2013

Gonzalez et al., 2013

Guéye et al., 2003

Horowitz et al., 1997

Isacco et al., 2012a

Isacco et al., 2012b

Kirwan et al., 2001a

Kirwan et al., 2001b

Little et al., 2009

Little et al., 2010

Massicotte et al., 1990

Montain et al., 1991a

Montain et al., 1991b

Ramos-Jiménez et al., 2014

Satabin et al., 1987

Schabort et al., 1999

Shin et al., 2013

Wu et al., 2003

Ziogas \& Thomas, 1998
Statistics for each study

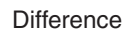

in means

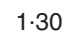

0.20

$-0.06$

0.93

0.94

0.21

$-0.04$

1.39

$2 \cdot 23$

0.55

0.39

1.26

3.26

$-0.27$

$-0.32$

0.15

0.06

0.47

0.41

$-0.11$

$-0.33$

$2 \cdot 49$

0.00

0.07

0.59

$0.18 \quad 0.03$
Lower Upper

SE Variance limit limit $Z$-value $P$

$\begin{array}{llllll}0.59 & 0.35 & 0.14 & 2.46 & 2.20 & 0.028\end{array}$

$\begin{array}{llllll}0.27 & 0.07 & -0.33 & 0.73 & 0.74 & 0.460\end{array}$

$\begin{array}{llllll}0.16 & 0.02 & -0.36 & 0.24 & -0.39 & 0.698\end{array}$

$\begin{array}{llllll}0.50 & 0.25 & -0.05 & 1.91 & 1.86 & 0.063\end{array}$

$\begin{array}{llllll}0.88 & 0.78 & -0.79 & 2.67 & 1.06 & 0.288\end{array}$

$\begin{array}{llllll}0.21 & 0.05 & -0.20 & 0.62 & 0.99 & 0.321\end{array}$

$\begin{array}{llllll}0.14 & 0.02 & -0.31 & 0.23 & -0.29 & 0.767\end{array}$

$\begin{array}{llllll}0.29 & 0.09 & 0.82 & 1.96 & 4.77 & 0.000\end{array}$

$\begin{array}{llllll}0.52 & 0.27 & 1.22 & 3.24 & 4.33 & 0.000\end{array}$

$\begin{array}{llllll}0.22 & 0.05 & 0.12 & 0.98 & 2.52 & 0.012\end{array}$

$\begin{array}{llllll}0.21 & 0.04 & -0.02 & 0.80 & 1.87 & 0.062\end{array}$

$\begin{array}{llllll}0.38 & 0.15 & 0.51 & 2.01 & 3.31 & 0.001\end{array}$

$\begin{array}{llllll}0.26 & 0.07 & 2.75 & 3.77 & 12.46 & 0.000\end{array}$

$\begin{array}{llllll}0.34 & 0.11 & -0.93 & 0.39 & -0.80 & 0.424\end{array}$

$\begin{array}{llllll}0.24 & 0.06 & -0.78 & 0.14 & -1.35 & 0.177\end{array}$

$\begin{array}{llllll}0.74 & 0.54 & -1.28 & 1.58 & 0.21 & 0.838\end{array}$

$\begin{array}{llllll}0.20 & 0.04 & -0.33 & 0.45 & 0.30 & 0.762\end{array}$

$\begin{array}{llllll}0.32 & 0.10 & -0.16 & 1.10 & 1.47 & 0.143\end{array}$

$\begin{array}{llllll}0.55 & 0.30 & -0.67 & 1.49 & 0.75 & 0.457\end{array}$

$\begin{array}{llllll}0.19 & 0.04 & -0.49 & 0.27 & -0.57 & 0.568\end{array}$

$\begin{array}{llllll}0.36 & 0.13 & -1.04 & 0.38 & -0.92 & 0.360\end{array}$

$\begin{array}{llllll}0.32 & 0.10 & 1.87 & 3.11 & 7.86 & 0.000\end{array}$

$\begin{array}{llllll}0.19 & 0.04 & -0.36 & 0.36 & 0.00 & 1.000\end{array}$

$\begin{array}{llllll}0.20 & 0.04 & -0.33 & 0.47 & 0.35 & 0.729\end{array}$

0.35
3.36

0.001

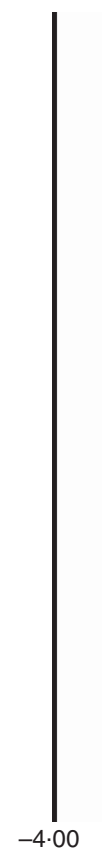

Difference in means and $95 \% \mathrm{Cl}$

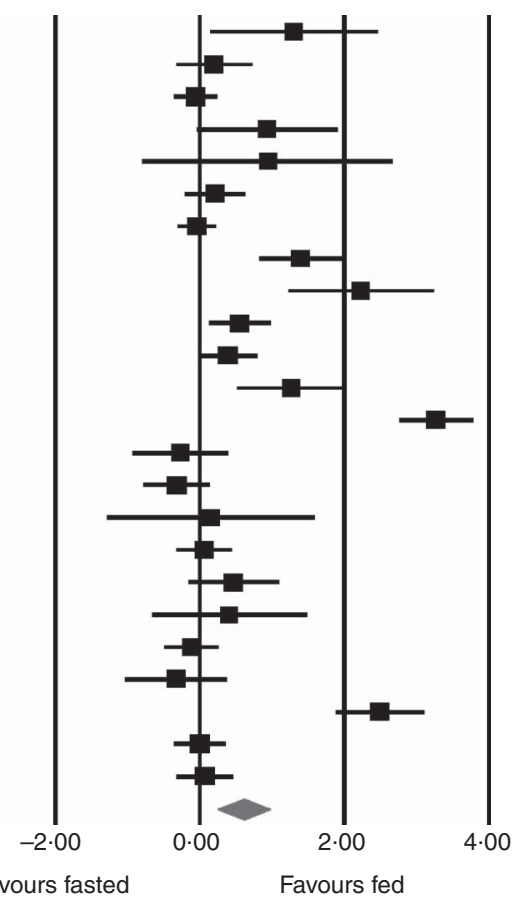

Fig. 6. Weighted mean difference of glucose concentrations (mmol/l) relative to exercise performed in the fasted state $v$. fed state. $\square$, Study-specific estimates: $\checkmark$, pooled estimates of random-effects meta-analyses.

Study name

$\begin{array}{lr} & \begin{array}{r}\text { Difference } \\ \text { in means }\end{array} \\ \text { Coyle et al., 1985 } & 32 \cdot 6 \\ \text { Coyle et al., 1997 } & 200 \cdot 4 \\ \text { Dohm et al., 1986 } & 165 \cdot 5 \\ \text { Gonzalez et al., 2013 } & 107 \cdot 5 \\ \text { Horowitz et al., 1997 } & 192 \cdot 5 \\ \text { Isacco et al., 2012a } & 103 \cdot 1 \\ \text { Isacco et al., 2012b } & 68 \cdot 7 \\ \text { Kirwan et al., 2001a } & 61 \cdot 2 \\ \text { Kirwan et al., 2001b } & 923 \cdot 7 \\ \text { Little et al., 2010 } & 15 \cdot 6 \\ \text { Massicotte et al., 1990 } & 45 \cdot 1 \\ \text { Montain et al., 1991a } & 82 \cdot 6 \\ \text { Montain et al., 1991b } & 188 \cdot 2 \\ \text { Schabort et al., 1999 } & -6.9 \\ \text { Shin et al., 2013 } & 196 \cdot 4 \\ \text { Whitley et al., 1998 } & 34.2 \\ \text { Wu et al., 2003 } & 188.9 \\ & 104.5\end{array}$

Statistics for each study

Difference in means and $95 \% \mathrm{Cl}$

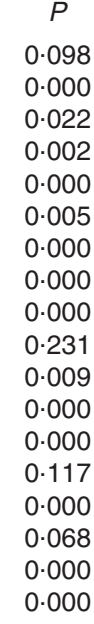

\begin{tabular}{|c|c|c|c|c|}
\hline SE & Variance & $\begin{array}{l}\text { Lower } \\
\text { limit }\end{array}$ & $\begin{array}{l}\text { Upper } \\
\text { limit }\end{array}$ & $z$ \\
\hline $19 \cdot 7$ & $386 \cdot 6$ & $-5 \cdot 9$ & $71 \cdot 1$ & $1 \cdot 7$ \\
\hline $47 \cdot 2$ & $2232 \cdot 1$ & $107 \cdot 8$ & 293.0 & 4 \\
\hline $72 \cdot 2$ & $5218 \cdot 9$ & 23.9 & $307 \cdot 1$ & 2 \\
\hline $35 \cdot 4$ & $1254 \cdot 6$ & $38 \cdot 1$ & $176 \cdot 9$ & $3 \cdot 0$ \\
\hline $45 \cdot 7$ & $2087 \cdot 7$ & $102 \cdot 9$ & $282 \cdot 0$ & $4 \cdot 2$ \\
\hline $37 \cdot 0$ & 137 & $30 \cdot 5$ & $175 \cdot 7$ & $2 \cdot 8$ \\
\hline $18 \cdot 2$ & 33 & 3.0 & $104 \cdot 3$ & $3 \cdot 8$ \\
\hline 9 & & 1.8 & $80 \cdot 6$ & $6 \cdot 2$ \\
\hline $25 \cdot 6$ & 577 & $677 \cdot 6$ & $1169 \cdot 9$ & $7 \cdot 4$ \\
\hline $13 \cdot 0$ & 170 & $-9 \cdot 9$ & $41 \cdot 2$ & $1 \cdot 2$ \\
\hline $17 \cdot 3$ & $300 \cdot 9$ & $11 \cdot 1$ & $79 \cdot 1$ & $2 \cdot 6$ \\
\hline $23 \cdot 6$ & $555 \cdot 6$ & $36 \cdot 4$ & $128 \cdot 8$ & 3.5 \\
\hline $49 \cdot 6$ & $2458 \cdot 4$ & $91 \cdot 0$ & $285 \cdot 4$ & 3.8 \\
\hline $4 \cdot 4$ & $19 \cdot 3$ & $-15 \cdot 5$ & $1 \cdot 7$ & $-1 \cdot 6$ \\
\hline $40 \cdot 1$ & $1610 \cdot 5$ & $117 \cdot 7$ & $275 \cdot 1$ & 4.9 \\
\hline $18 \cdot 7$ & 349.5 & $-2 \cdot 5$ & $70 \cdot 8$ & 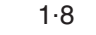 \\
\hline $42 \cdot$ & 1833 & $104 \cdot 9$ & $272 \cdot 8$ & 4 \\
\hline 17.2 & $295 \cdot 2$ & $70 \cdot 8$ & $138 \cdot 2$ & 6. \\
\hline
\end{tabular}

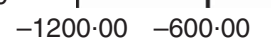

Favours fasted

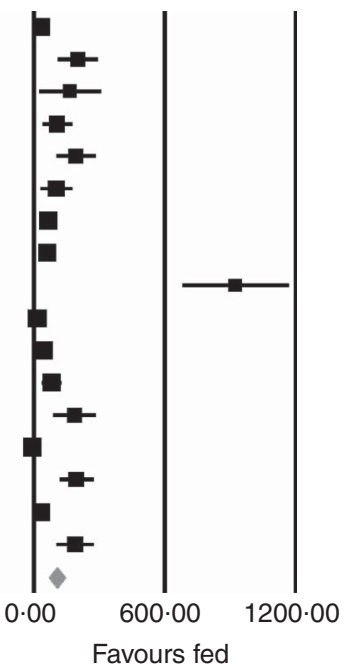

Fig. 7. Weighted mean difference of insulin concentrations (pmol/l) relative to exercise performed in the fasted state $v$. fed state $\bullet$, pooled estimates of random-effects meta-analyses.

fasted and fed states during exercises at intensities $\geq 70 \%$ $\mathrm{VO}_{2 \max }$. These findings confirm the results reported by Bergman \& Brooks ${ }^{(30)}$, in which the effect of intensity and previous feeding on energy substrate used during exercise was verified. Higher fat oxidation was observed in the fasted state, compared with the fed state, during exercises with intensities up to $59 \% \mathrm{VO}_{2 \text { peak }}$, but not at the intensity of $75 \% \mathrm{VO}_{2 \text { peak }}$.

The literature reports that physical training is able to reduce insulin resistance ${ }^{(14)}$ related to excessive accumulation of IMTG in sedentary individuals ${ }^{(62)}$. This effect seems to be due to increased fat oxidation ${ }^{(15)}$, mainly coming from fatty acids 
derived from $\mathrm{IMTG}^{(63)}$. The acute effects of exercise in the fasted state are able to reduce the content of IMTG by approximately $60 \%{ }^{(5,64)}$, which does not seem to occur in the fed state ${ }^{(5)}$ and, in the long term, seems to be more effective in improving insulin sensitivity ${ }^{(65)}$.

Venables \& Jeukendrup ${ }^{(14)}$ demonstrated that an increase in fat oxidation of approximately $3 \mathrm{~g}$ during $30 \mathrm{~min}$ of aerobic exercise was able to enhance insulin sensitivity in obese and sedentary men. The present meta-analysis indicates that aerobic exercise performed in the fasted state provides an increase in fat oxidation of about $3.08 \mathrm{~g}$ during the session compared with the fed state. Therefore, it is suggested that exercising in the fasted state can be an alternative to increase the use of fat as the energy source and the increase of oxidised fats by $3.08 \mathrm{~g}$ during an exercise session may be sufficient to induce improvements in insulin sensitivity.

As previously described, it is well established that plasma concentrations of NEFA are higher in the fasted states compared with fed states ${ }^{(4,66,67)}$. However, our results indicate that the magnitude of variation, from before to after exercise, does not appear to differ between fasted $v$. fed states. In general, during the first $15 \mathrm{~min}$ of exercise, plasma NEFA concentrations decrease, as the utilisation rate in the muscles exceeds the lipolysis-driven release rate. After this period, the release rate exceeds use in the muscles and the fatty acid concentrations in the plasma rise ${ }^{(4)}$. On the basis of the results provided in this meta-analysis, this event seems to occur in similar ways in both fasted and fed states.

Although the weighted mean difference of NEFA showed no significant differences, the present study demonstrates that variation in glucose and insulin concentrations before and after exercise was significantly higher during exercise performed in the fed state. One possible explanation for this finding in relation to insulin is that carbohydrate ingestion before exercise can result in a considerable increase in insulin concentrations ${ }^{(68)}$, which may remain high for about $3 \mathrm{~h}$ after consuming a meal ${ }^{(51)}$, and tend to return to basal values when exercise is performed ${ }^{(45,47)}$. In this case, it is noteworthy that the majority of studies included in the meta-analysis offered meals up to $180 \mathrm{~min}$ before exercising $^{(6,7,31,32,37,38,47-52)}$. Hence, it is probable that insulin concentrations remained high at the beginning of exercise and decreased over the course of the exercise for 'fed state' participants.

Regarding glucose concentrations, the highest variation generated by exercise performed in the fed state is attributed to increased glucose concentrations in plasma, due to the intake of carbohydrates before exercise, and subsequent fall in glucose concentration due to the combined effects of hyperinsulinaemia and glucose uptake for use as an energy substrate in muscle contractile activity ${ }^{(6,69)}$. On the other hand, fasting causes increases in glycerol release through hydrolysis of TAG molecules from fat cells; this is a valuable precursor for hepatic gluconeogenesis, thus contributing to the availability of glucose $^{(2)}$. These principles can be used to explain the greater variations in plasma glucose concentration in the fed state relative to the fasted state. When sensitivity analyses were performed for this variable according to the criterion 'quantity of carbohydrate consumed in the pre-exercise meal $\geq 100$ g', meta-analysis did not demonstrate a significant difference in the variation of glucose between fasted $v$. fed states.
A possible hypothesis for this is that the intake of carbohydraterich meals increases the availability of glucose during exercise $^{(68)}$.

Although this systematic review with meta-analysis was performed with the maximum methodological rigour possible, some limitations should be highlighted. First was the inclusion of different intensities and durations of exercise, sex, times between meals and exercise, types of meals and quality and quantity of carbohydrates: in spite of methodological differences between the studies under review, we sought to maximise standardisation in the data examined. Second, as many relatively old publications were included in this study, certain methodological limitations and flaws were noted in the presentation of data. We would like to emphasise in particular that the large number of trials with results presented exclusively in graphs, and the lack of provision of these data (means and standard deviations) from authors, limited the accuracy of data extraction. Third, most of the studies included in the analyses of glucose concentrations assessed glucose levels using venous blood sampling. Previous studies have reported $^{(70,71)}$ that the arterial sampling would be more recommended to assess glucose levels; however, venous blood sampling is the most commonly used method and it is widely accepted. In addition, high heterogeneity was identified in metaanalyses related to blood molecular concentrations, necessitating caution in interpreting these data.

Is worth mentioning that, although our results have shown increased fat oxidation during exercise performed in the fasted state, it is necessary to take care when prescribing this strategy in practice, as this meta-analysis was performed using only data assessing the acute effects of exercise during fasting $v$. fed states. The findings should not be extrapolated as long-term effects, especially with the aim of reducing body fat, as there is insufficient evidence of effectiveness and safety.

\section{Conclusion}

This systematic review with meta-analysis suggests that aerobic exercise at low-to-moderate intensity, performed in the fasted state, induces an increase in fat oxidation, when compared with exercise performed following consumption of a carbohydratecontaining meal. Despite high heterogeneity of the data, no difference appears to exist between exercising in the fasted or fed states in relation to variations in NEFA concentrations before and after exercise. In contrast, variation in relation to glucose and insulin concentrations appears to be higher in the fed states. Future meta-analyses and randomised clinical trials, inclusive of an evaluation of the long-term effects of aerobic exercise on fat and carbohydrate metabolism in the fasted and fed states, will be necessary to confirm the findings of the present review, as well as to identify their real benefits or consequences for long-term health.

\section{Acknowledgements}

The authors thank François Péronnet, Jonathan Little, John Kirwan, Laurie Isacco, Nathalie Boisseau, Bryan Bergman, 
Karen Soo, Donald Chisholm and Katarina Borer, all of whom answered our questions by email

The present study was supported by the following organisations: CAPES, CNPq and FAURGS.

The authors' contributions are as follows: A. F. V., R. C. O. M. and R. R. C. formulated the research questions; A. F. V., R. C. O. M., R. R. C. and L. F. M. K. designed the study and A. F. V., R. R. C. and L. C. performed the study; A. F. V. and R. R. C. analysed the data; A. F. V., R. R. C. and R. C. O. M. wrote the paper. All the authors critically reviewed and improved the manuscript.

The authors declare that there are no conflicts of interest.

\section{Supplementary material}

For supplementary material/s referred to in this article, please visit http://dx.doi.org/doi:10.1017/S0007114516003160

\section{References}

1. Longo VD \& Mattson MP (2014) Fasting: molecular mechanisms and clinical applications. Cell Metab 19, 181-192.

2. Maughan RJ, Fallah J \& Coyle EF (2010) The effects of fasting on metabolism and performance. Br J Sports Med $\mathbf{4 4}$, 490-494.

3. Cahill GF Jr (2006) Fuel metabolism in starvation. Annu Rev Nutr 26, 1-22.

4. Jeukendrup AE (2003) Modulation of carbohydrate and fat utilization by diet, exercise and environment. Biochem Soc Trans 31, 1270-1273.

5. De Bock K, Richter EA, Russell AP, et al. (2005) Exercise in the fasted state facilitates fibre type-specific intramyocellular lipid breakdown and stimulates glycogen resynthesis in humans. J Physiol 564, 649-660.

6. Horowitz JF, Mora-Rodriguez R, Byerley LO, et al. (1997) Lipolytic suppression following carbohydrate ingestion limits fat oxidation during exercise. Am J Physiol 273, E768-E775.

7. Coyle EF, Jeukendrup AE, Wagenmakers AJ, et al. (1997) Fatty acid oxidation is directly regulated by carbohydrate metabolism during exercise. Am J Physiol 273, E268-E275.

8. Spriet LL (2014) New insights into the interaction of carbohydrate and fat metabolism during exercise. Sports Med $\mathbf{4 4}$, S87-S96.

9. Bassuk SS \& Manson JE (2005) Epidemiological evidence for the role of physical activity in reducing risk of type 2 diabetes and cardiovascular disease. J Appl Physiol 99, 1193-1204.

10. Donnelly JE, Blair SN, Jakicic JM, et al. (2009) American College of Sports Medicine Position Stand. Appropriate physical activity intervention strategies for weight loss and prevention of weight regain for adults. Med Sci Sports Exerc 41, 459-471.

11. Slentz CA, Duscha BD, Johnson JL, et al. (2004) Effects of the amount of exercise on body weight, body composition, and measures of central obesity. Arch Intern Med 164, 31-39.

12. Goodpaster BH, Katsiaras A \& Kelley DE (2003) Enhanced fat oxidation through physical activity is associated with improvements in insulin sensitivity in obesity. Diabetes $\mathbf{5 2}$, 2191-2197.

13. Rosenkilde M, Nordby P, Nielsen LB, et al. (2010) Fat oxidation at rest predicts peak fat oxidation during exercise and metabolic phenotype in overweight men. Int J Obes 34, 871-877.

14. Venables MC \& Jeukendrup AE (2008) Endurance training and obesity: effect on substrate metabolism and insulin sensitivity. Med Sci Sports Exerc 40, 495-502.
15. Robinson SL, Hattersley J, Frost GS, et al. (2015) Maximal fat oxidation during exercise is positively associated with 24-hour fat oxidation and insulin sensitivity in young, healthy men. J Appl Physiol 118, 1415-1422.

16. Burton FL, Malkova D, Caslake MJ, et al. (2010) Substrate metabolism, appetite and feeding behavior under low and high energy turnover conditions in overweight women. Br J Nutr 104, 1249-1259.

17. Iwayama K, Kawabuchi R, Park I, et al. (2015a) Transient energy deficit induced by exercise increases 24 -h fat oxidation in young trained men. $J$ Appl Physiol 118, 80-85.

18. Iwayama K, Kurihara R, Nabekura Y, et al. (2015b) Exercise increases 24-h fat oxidation only when it is performed before breakfast. EBioMedicine 2, 2003-2009.

19. Shimada K, Yamamoto Y, Iwayama K, et al. (2013) Effects of post-absorptive and postprandial exercise on $24 \mathrm{~h}$ fat oxidation. Metabolism 62, 793-800.

20. Enevoldsen LH, Simonsen L, Macdonald IA, et al. (2004) The combined effects of exercise and food intake on adipose tissue and splanchnic metabolism. J Physiol 561, 871-882.

21. Lee BM \& Wolever TMS (1998) Effect of glucose, sucrose and fructose on plasma glucose and insulin responses in normal humans: comparison with white bread. Eur J Clin Nutr 52, 924-928.

22. Liberati A, Altman DG, Tetzlaff J, et al. (2009) The PRISMA statement for reporting systematic reviews and meta-analyses of studies that evaluate health care interventions: explanation and elaboration. Ann Intern Med 151, W-65-W-94.

23. Shamseer L, Moher D, Clarke M, et al. (2015) Preferred Reporting Items for Systematic Review and Meta-Analysis Protocols (PRISMA-P) 2015: elaboration and explanation. BMJ 349, 1-25.

24. Péronnet F \& Massicotte D (1991) Table of nonprotein respiratory quotient: an update. Can J Sport Sci 16, 23-29.

25. Jeukendrup AE \& Wallis GA (2005) Measurement of substrate oxidation during exercise by means of gas exchange measurements. Int J Sports Med 26, S28-S37.

26. Deeks JJ, Higgins JPT \& Altman DG (editors) (2011) Chapter 9: Analysing data and undertaking meta-analysis. In Cochrane Handbook for Systematic Reviews of Interventions, Version 5.1.0 (updated March 2011) [JPT Higgins and S Green, editors]. The Cochrane Collaboration. http://handbook.cochrane.org/ CCAa (accessed September 2015).

27. Higgins JPT, Deeks JJ \& Altman DG (editors) (2008) Chapter 16: Special topics in statistics. In Cochrane Handbook for Systematic Reviews of Interventions, Version 5.0.1 (updated September 2008) [JPT Higgins and S Green, editors]. The Cochrane Collaboration. http://www.cochrane-handbook.org (accessed July 2015).

28. Higgins JPT, Thompson SG, Deeks JJ, et al. (2003) Measuring inconsistency in meta-analyses. BMJ 327, 557-560.

29. Egger M, Davey Smith G, Schneider M, et al. (1997) Bias in meta-analysis detected by a simple, graphical test. BMJ $\mathbf{3 1 5}$, 629-634.

30. Bergman BC \& Brooks GA (1999a, b) Respiratory gasexchange ratios during graded exercise in fed and fasted trained and untrained men. J Appl Physiol 86, 479-487.

31. Isacco L, Thivel D, Pelle AM, et al. (2012a, b) Oral contraception and energy intake in women: impact on substrate oxidation during exercise. Appl Physiol Nutr Metab 37, 646-656.

32. Montain SJ, Hopper MK, Coggan AR, et al. (1991a, b) Exercise metabolism at different time intervals after a meal. $J$ Appl Physiol 70, 882-888.

33. Drenick EJ, Fisler JS, Johnson DG, et al. (1977) The effect of exercise on substrates and hormones during prolonged fasting. Int J Obes 1, 49-61. 
34. Borer KT, Wuorinen E, Chao C, et al. (2005) Exercise energy expenditure is not consciously detected due to oro-gastric, not metabolic, basis of hunger sensation. Appetite 45, 177-181.

35. Erdmann J, Tholl S \& Schusdziarra V (2010) Effect of carbohydrate- and protein-rich meals on exercise-induced activation of lipolysis in obese subjects. Horm Metab Res 42, 290-294.

36. Little JP, Chilibeck PD, Ciona D, et al. (2009) The effects of low- and high-glycemic index foods on high-intensity intermittent exercise. Int J Sports Physiol Perform 4, 367-380.

37. Schabort EJ, Bosch AN, Weltan SM, et al. (1999) The effect of a preexercise meal on time to fatigue during prolonged cycling exercise. Med Sci Sports Exerc 31, 464-471.

38. Shin YH, Jung HL, Ryu JW, et al. (2013) Effects of a preexercise meal on plasma growth hormone response and fat oxidation during walking. Prev Nutr Food Sci 18, 175-180.

39. Farah NMF \& Gill JMR (2013) Effects of exercise before or after meal ingestion on fat balance and postprandial metabolism in overweight men. Br J Nutr 109, 2297-2307.

40. Maughan RJ \& Gleeson M (1988) Influence of a $36 \mathrm{~h}$ fast followed by refeeding with glucose, glycerol or placebo on metabolism and performance during prolonged exercise in man. Eur J Appl Physiol 57, 570-576.

41. Paul GL, Rokusek JT, Dykstra GL, et al. (1996) Oat, wheat or corn cereal ingestion before exercise alters metabolism in humans. J Nutr 126, 1372-1381.

42. Satabin P, Portero P, Defer G, et al. (1987) Metabolic and hormonal responses to lipid and carbohydrate diets during exercise in man. Med Sci Sports Exerc 19, 218-223.

43. Whitley HA, Humphreys SM, Campbell IT, et al. (1998) Metabolic and performance responses during endurance exercise after high-fat and high-carbohydrate meals. J Appl Physiol 85, 418-424.

44. Willcutts KF, Wilcox AR \& Grunewald KK (1988) Energy metabolism during exercise at different time intervals following a meal. Int J Sports Med 9, 240-243.

45. Coyle EF, Coggan AR, Hemmert MK, et al. (1985) Substrate usage during prolonged exercise following a preexercise meal. J Appl Physiol 59, 429-433.

46. Dohm GL, Beeker RT, Israel RG, et al. (1986) Metabolic responses to exercise after fasting. J Appl Physiol 61, 1363-1368.

47. Gonzalez JT, Veasey RC, Rumbold PLS, et al. (2013) Breakfast and exercise contingently affect postprandial metabolism and energy balance in physically active males. Br J Nutr 110, 721-732.

48. Kirwan JP, Cyr-Campbell D, Campbell WW, et al. (2001a) Effects of moderate and high glycemic index meals on metabolism and exercise performance. Metabolism 50, 849-855.

49. Kirwan JP, O'Gorman DJ, Cyr-Campbell D, et al. (2001b) Effects of a moderate glycemic meal on exercise duration and substrate utilization. Med Sci Sports Exerc 33, 1517-1523.

50. Little JP, Chilibeck PD, Ciona D, et al. (2010) Effect of low and high glycemic-index meals on metabolism and performance during high-intensity, intermittent exercise. Int J Sport Nutr Exerc Metab 20, 447-456.

51. Wu CL, Nicholas C, Williams C, et al. (2003) The influence of high-carbohydrate meals with different glycaemic indices on substrate utilisation during subsequent exercise. BrJ Nutr 90 , 1049-1056.

52. Massicotte D, Péronnet F, Brisson G, et al. (1990) Oxidation of exogenous carbohydrate during prolonged exercise in fed and fasted conditions. Int J Sports Med 11, 253-258.
53. Aziz AR, Wahid MF, Png W, et al. (2010) Effects of Ramadan fasting on $60 \mathrm{~min}$ of endurance running performance in moderately trained men. Br J Sports Med $\mathbf{4 4}$, $516-521$

54. Bouhlel E, Salhi Z, Bouhlel H, et al. (2006) Effect of Ramadan fasting on fuel oxidation during exercise in trained male rugby players. Diabetes Metab 32, 617-624.

55. Guéye L, Seck D, Samb A, et al. (2003) Physiological adaptations to exercise during a short-term fasting. Scr Med (Brno) 76, 291-296.

56. Ramos-Jiménez A, Anguiano-Juarez J, Sifuentes-Juarez A, et al. (2014) Fasting and postprandial glycemia in response to a strenuous workout in healthy subjects with family history of diabetes and borderline insulin resistance. Exp Clin Cardiol 20, 139-161.

57. Ziogas G \& Thomas TR (1998) Dietary preparation before rest and exercise testing. Nutrition 14, 11-16.

58. Horowitz JF \& Klein S (2000) Lipid metabolism during endurance exercise. Am J Clin Nutr 72, 558S-563S.

59. Arner P, Kriegholm E, Engfeldt P, et al. (1990) Adrenergic regulation of lipolysis in situ at rest and during exercise. J Clin Invest 85, 893-898.

60. Achten J \& Jeukendrup AE (2004) Optimizing fat oxidation through exercise and diet. Nutr 20, 716-727.

61. van Loon LJ, Greenhaff PL, Constantin-Teodosiu D, et al. (2001) The effects of increasing exercise intensity on muscle fuel utilization in humans. J Physiol 536, 295-304.

62. Kelley DE \& Goodpaster BH (2001) Skeletal muscle triglyceride. An aspect of regional adiposity and insulin resistance. Diabetes Care 24, 933-941.

63. Schrauwen P, van Aggel-Leijssen DP, Hul G, et al. (2002) The effect of a 3-month low-intensity endurance training program on fat oxidation and acetyl-CoA carboxylase-2 expression. Diabetes 51, 2220-2226.

64. van Loon LJC, Koopman R, Stegen JHCH, et al. (2003) Intramyocellular lipids form an important substrate source during moderate intensity exercise in endurance-trained males in a fasted state. J Physiol 553, 611-625.

65. Van Proeyen K, Szlufcik K, Nielens H, et al. (2010) Training in the fasted state improves glucose tolerance during fatrich diet. J Physiol 588, 4289-4302.

66. Sahlin K \& Harris RC (2008) Control of lipid oxidation during exercise: role of energy state and mitochondrial factors. Acta Physiol (Oxf) 194, 283-291.

67. Spriet LL \& Watt MJ (2003) Regulatory mechanisms in the interaction between carbohydrate and lipid oxidation during exercise. Acta Physiol Scand 178, 443-452.

68. Hargreaves M, Hawley JA \& Jeukendrup A (2004) Pre-exercise carbohydrate and fat ingestion: effects on metabolism and performance. J Sports Sci 22, 31-38.

69. Marmy-Conus N, Fabris S, Proietto J, et al. (1996) Pre-exercise glucose ingestion and glucose kinetics during exercise. $J A p p l$ Physiol 81, 853-857.

70. Liu D, Moberg E, Kollind M, et al. (1992) Arterial, arterialized venous, venous and capillary blood glucose measurements in normal man during hyperinsulinaemic euglycaemia and hypoglycaemia. Diabetologia 35, 287-290.

71. Brouns F, Bjorck I, Frayn KN, et al. (2005) Glycaemic index methodology. Nutr Res Rev 18, 145-171. 